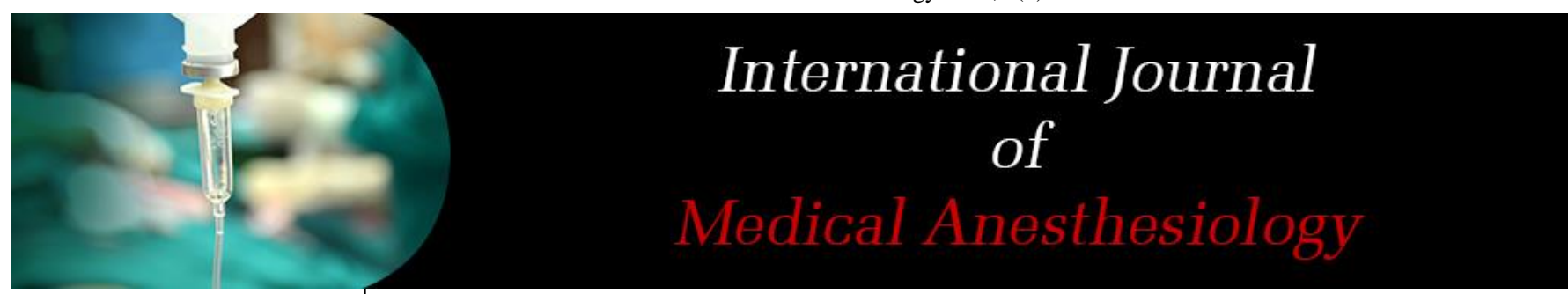

E-ISSN: 2664-3774

P-ISSN: 2664-3766

www.anesthesiologypaper.com

IJMA 2020; 3(2): 01-05

Received: 01-05-2020

Accepted: 02-06-2020

Dr. Nitish Gupta

Senior Resident, Department of Anesthesia MGM Medical

College \& Hospital

Aurangabad, Maharashatra,

MGM University, Navi

Mumbai, Maharashtra, India

Dr. Sanhita J Kulkarni

Professor \& H.O.D,

Department of Anesthesia

MGM Medical College \&

Hospital Aurangabad,

Maharashatra, MGM

University, Navi Mumbai,

Maharashtra, India

Dr. Vasanti M Sasturkar

Professor, Department of Anesthesia MGM Medical College \& Hospital

Aurangabad, Maharashatra, MGM University, Navi

Mumbai, Maharashtra, India

Dr. PV Bhale

Professor, Department of Anesthesia MGM Medical College \& Hospital

Aurangabad, Maharashatra, MGM University, Navi

Mumbai, Maharashtra, India

Dr. Pradnya S Joshi Associate Professor, Department of Anesthesia MGM Medical College \& Hospital Aurangabad, Maharashatra, MGM University, Navi Mumbai, Maharashtra, India

Corresponding Author: Dr. Pradnya S Joshi Associate Professor, Department of Anesthesia MGM Medical College \& Hospital Aurangabad, Maharashatra, MGM University, Navi Mumbai, Maharashtra, India

\section{Comparative study of efficacy of intrathecal bupivacaine-ketamine with bupivacaine-fentanyl for caesarean section}

\author{
Dr. Nitish Gupta, Dr. Sanhita J Kulkarni, Dr. Vasanti M Sasturkar, Dr. \\ PV Bhale and Dr. Pradnya S Joshi
}

DOI: https://doi.org/10.33545/26643766.2020.v3.i3a.134

\section{Abstract}

Background: Various adjuvants have been used with local anaesthetics in spinal anaesthesia for lower segment caesarean section (LSCS) to provide better haemodynamics \& prolonged postoperative analgesia. The aim of this study was to compare onset \& duration of sensory \& motor block with haemodynamic stability of intrathecal ketamine and fentanyl added to Bupivacaine in spinal anaesthesia for two different group of patients posted for LSCS

Method: Sixty patients of age between 18-35 years and ASA grade I and II were included and randomly divided in to two groups of 30 each. Group K received injection bupivacaine $10 \mathrm{mg}$ with 10 $\mathrm{mg}$ Ketamine and Group F received injection Bupivacaine $10 \mathrm{mg}$ with $12.5 \mathrm{mcg}$ Fentanyl. The sensorimotor characteristics, haemodynamic parameters, neonatal outcome and side effects were noted and compared between two groups.

Results: Group K showed higher sensory level $(<0.05)$, rapid sensory $(P<0.05)$ and motor $(P<0.05)$ onsets, prolonged sensory $(P<0.05)$ and motor $(P<0.05)$ blocks as compared to group F.Hyperbaric bupivacaine- Ketamine had better haemodynamic stability and significantly reduced incidence of hypotension $(P<0.05)$ and bradycardia $(P<0.05)$. Apgar scores at 1 and 5 min were comparable in both groups $(\mathrm{P}=0.2734$ and 0.6731 respectively). Tachycardia was found in $16.66 \%$ cases in group $\mathrm{K}$, whereas no patient developed tachycardia in group $\mathrm{F}$.

Conclusion: The combination of hyperbaric bupivacaine $(0.5 \%) 10 \mathrm{mg}$ with ketamine $(10 \mathrm{mg})$ can be used as a safe and effective alternative to hyperbaric bupivacaine $(0.5 \%) 10 \mathrm{mg}$ with fentanyl $12.5 \mathrm{mcg}$ for spinal anaesthesia in LSCS.

Keywords: bupivacaine, fentanyl, ketamine, spinal anaesthesia

\section{Introduction}

Spinal anaesthesia (SA) is the most widely used anaesthetic technique for caesarean section. It produces rapid onset of analgesia and complete muscle relaxation. Risk of aspiration, drug induced neonatal depression associated with general anaesthesia may largely be avoided by using neuraxial techniques ${ }^{[1]}$. Bupivacaine a long acting amide is the most popular local anaesthetic agent used for spinal anaesthesia in parturient undergoing LSCS. Commonly used dose of bupivacaine $(10-15 \mathrm{mg})$ is associated with hypotension and longer duration of motor block ${ }^{[2,3]}$. Decreasing the dose of bupivacaine in spinal anaesthesia helps to minimize these adverse effects but simultaneously may result in anaesthetic failure. To avoid such instances many drugs such as opioids (morphine, fentanyl), midazolam, clonidine, ketamine have been used as adjuvant to bupivacaine ${ }^{[3]}$.

In parturient most commonly used adjuvant is fentanyl. Since fentanyl is lipophilic opioid, when used intrathecally, there is minimal cephalad spread thus least likely to cause delayed respiratory depression compared to morphine ${ }^{[5]}$. Ketamine, a phencyclidine derivative and commonly used intravenous induction agent, has been also found to be effective by intrathecal route. Intrathecal ketamine possesses some definitive advantages such as stimulation of cardiovascular system thus decreasing incidence of hypotension ${ }^{[7,8]}$.

There are very few studies that had used intrathecal ketamine as an adjuvant in caesarean section. Hence this study was undertaken to assess the efficacy of intrathecal ketamine (10mg) compared to fentanyl $(12.5 \mathrm{mcg})$ in above mentioned doses along with bupivacaine (10mg) in parturient undergoing caesarean section. 


\section{Material and Methods}

After obtaining Institutional Ethical Committee approval and written informed consent from patients, this prospective, randomized, double blind study was conducted in 60 patients of ASA grade I and II, age between18-35 years, height $150-170 \mathrm{cms}$, weight $50-80 \mathrm{kgs}$, gestational age $>37$ weeks posted for elective caesarean section delivery from May 2016 to May 2018. Patients having contraindication for spinal anaesthesia such as coagulation disorder, local infection at the site of spinal anaesthesia, known allergy to local anaesthetics, foetal distress, patients with medical disorders like pregnancy induced hypertension, heart disease were excluded from the study. Using a sealed envelope method 60 patients was randomly allocated into two groups of 30 patients in each group. Group K: 0.5\% Hyperbaric Bupivacaine $10 \mathrm{mg}$ plus Ketamine $10 \mathrm{mg}$ and Group F: $0.5 \%$ Hyperbaric Bupivacaine $10 \mathrm{mg}$ plus Fentanyl $12.5 \mathrm{mcg}$.

All patients were kept nil orally for 6 hours. After shifting the patients in operation theatre (OT) baseline heart rate, non-invasive blood pressure, spo2, Electrocardiogram was recorded. With the help of $20 \mathrm{G}$ canula, IV line was established. One anaesthetist prepared the drugs and gave spinal anaesthesia, other anaesthetist (observer) who was blind to the study drug used, monitored the patient in the intra operative period and collected the data. Spinal anaesthesia was performed in sitting position with 23 gauge Quincke spinal needle by midline approach at L3-L4 level. After confirming free flow of CSF, study drug was injected in sub-arachnoid space and patient was made supine. After spinal anaesthesia the vital parameters pulse rate, BP (systolic, diastolic \& mean), respiratory rate and SPO2 were recorded at every 2 min for the first 10 minutes followed by every 5 minutes till the completion of surgery. Onset of sensory block was evaluated by pinprick method for 10 minutes at every 1 minute upto T10 level. The time from spinal injection (T-0) to time taken to achieve T10 level was taken as onset of sensory blockade and thereafter sensory block was tested every 5 min till the block regression to L1 level. Three consecutive reading at the same dermatome level was considered as highest level of sensory block. Duration of sensory block was defined as time period from beginning of sensory block to regression of sensory level to L1 dermatome. Motor block was assessed by modified Bromage scale $(0=$ No paralysis, able to flex hip $/ \mathrm{knee}$ joints/ankles, $1=$ able to move knees, unable to raise extended legs, $2=$ able to flex ankles, unable to flex knees, $3=$ unable to move any part of the lower limb). Motor block was evaluated for the 10 minute at every 1 minute. Onset of motor block was defined as time to achieve grade 3 motor block from time of intrathecal injection of drug and regression of motor block was taken as time to achieve grade 0 on bromage scale. Surgery was allowed after achieving T6 sensory level and grade 3 motor blocks. Failure to achieve loss of pin prick sensation at T6 dermatome level at the end of $20 \mathrm{~min}$ was considered as failure of block and general anaesthesia was supplemented. Neonatal outcome was assessed by the Apgar score at first and fifth minute.

Bradycardia was defined as pulse rate $<60 \mathrm{bpm}$ and treated with $0.3 \mathrm{mg}$ IV Atropine. Tachycardia, defined as pulse rate $>100 \mathrm{bpm}$, was treated with inj esmolol 10mg in incremental doses provided there is no associated hypotension. Hypotension was defined as decreased systolic pressure of $>20 \%$ of baseline value, and was treated with IV fluid boluses and inj mephenteramine in incremental doses of $3 \mathrm{mg}$. Side effects such as nausea, nystagmus, pruritus and vomiting were noted.

\section{Statistical analysis}

For calculating sample Size, following formula was applied:

$n=\frac{2 \times \mathrm{SD}^{2}\left(Z_{\alpha / 2}+Z_{\beta}\right)^{2}}{d^{2}}$

Where SD $=$ Pooled Standard Deviation

$Z_{\alpha / 2}=Z_{0.005 / 2}=1.96$ at type I error

$\mathrm{Z}_{\beta}=\mathrm{Z}_{0.20}=0.84$ at $80 \%$ power0

$\mathrm{d}=$ effect Size - difference between two mean

$n=\frac{2 \times(31.82)^{2} \times 7.84}{-----------------~} 20.25$

$(28)^{2}$

Minimum sample size required is 20 (approximately). Considering the drop-out; we included 30 patients in each group.

For the analysis of collected data SPSS version 20th was applied. The qualitative data was represented in form of frequency and percentage. The quantitative data was represented in form of Mean, SD etc. Both these qualitative and quantitative data was represented on visual impression like bar diagram, pie diagram. A $\mathrm{p}$ value $<0.05$ was considered statistically significant.

\section{Observations and results}

Sixty patients posted for elective caesarean section delivery were enrolled and divided into two groups of 30 patients in each. Both the groups were comparable with respect to the mean age, weight, height and duration of surgery $(p>0.05)$ as shown in table 1 .

Table 1: Demographic data and duration of surgery

\begin{tabular}{|c|c|c|c|}
\hline \multirow{2}{*}{ Parameters } & \multicolumn{2}{|c|}{ Mean \pm SD } & \multirow{2}{*}{ P value } \\
\cline { 2 - 3 } & Group K & Group F & \\
\hline Age (in years) & $23.63 \pm 2.53$ & $24.3 \pm 2.59$ & 0.5475 \\
\hline Weight (kg) & $53.67 \pm 3.54$ & $53.7 \pm 3.00$ & 0.9719 \\
\hline Height in Cm & $154.97 \pm 3.84$ & $154.47 \pm 3.61$ & 0.6053 \\
\hline Duration of Surgery & $54.97 \pm 3.84$ & $54.47 \pm 3.61$ & 0.7217 \\
\hline
\end{tabular}

The onset of sensory and motor block was significantly faster and total duration of sensory and motor block was significantly prolonged in ketamine group as compared to fentanyl group, ( $p$ value $<0.05)$. The mean time of sensory and motor characteristics is shown in table 2.

Table 2: Comparison of sensory and motor characteristics between two groups

\begin{tabular}{|c|c|c|c|}
\hline \multirow{2}{*}{ Variables (min) } & \multicolumn{2}{|c|}{ Mean \pm SD } & \multirow{2}{*}{ P value } \\
\cline { 2 - 4 } & Group K & Group F & \\
\hline Time of onset of sensory block & $2.72 \pm 0.51$ & $3.87 \pm 0.47$ & $<0.05$ \\
\hline Time for sensory regression to L1 & $168.23 \pm 5.51$ & $162.3 \pm 2.33$ & $<0.05$ \\
\hline Onset of motor block & $3.40 \pm 0.64$ & $6.62 \pm 0.54$ & $<0.05$ \\
\hline Time of complete motor recovery & $160.66 \pm 4.61$ & $150.3 \pm 4.21$ & $<0.05$ \\
\hline
\end{tabular}

In both the groups median level of maximum sensory block achieved was T6. In group $\mathrm{K}$, sensory block up to T4 was 
achieved in $16.67 \%$ patients (5 patients) and in group $\mathrm{F}$

$1)$. $43.33 \%$ patients achieved T4 level $(p$ value $<0.05$ ), (Figure

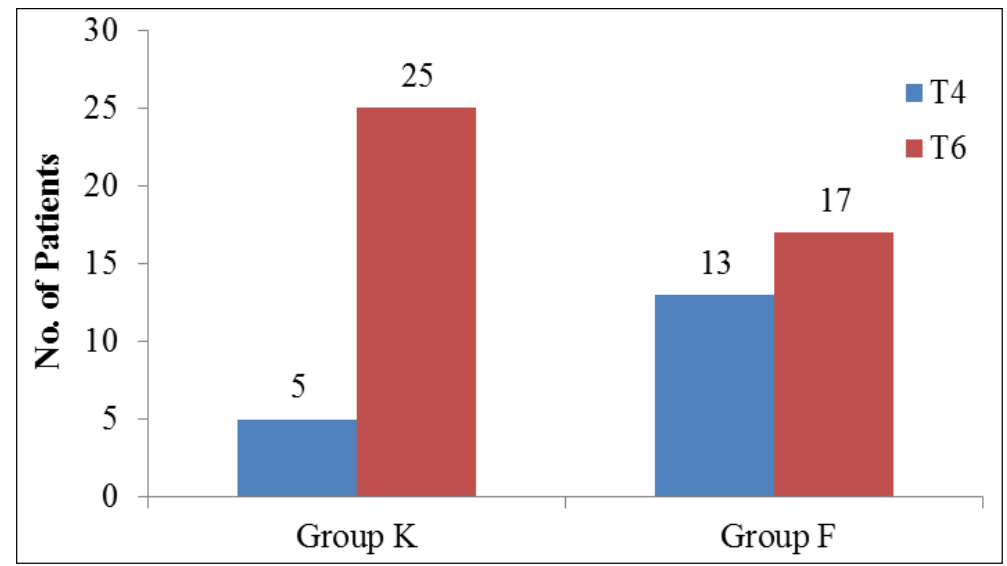

Fig 1: Comparison of highest level of sensory block between two groups

Apgar scores at 1 and $5 \mathrm{~min}$ were comparable in both the groups $(\mathrm{P}=0.2734$ and 0.6731 respectively) as depicted in

figure 2 .

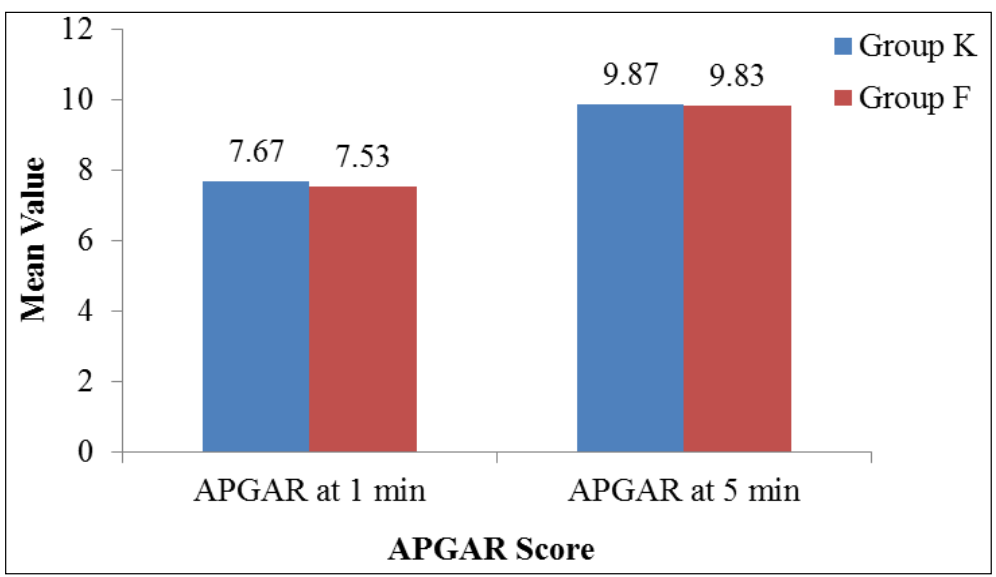

Fig 2: Comparison of mean Apgar score between two groups

The preoperative vitals (HR, SBP, DBP and MAP) were comparable between the two groups with no statistically significant differences $(p>0.05)$. Pulse rate (PR) in group $\mathrm{K}$ was on higher side at 2,120,150 minutes than in group $\mathrm{F}$ which was statistically significant $(p$ value $<0.05$ ). Systolic blood pressure (SBP) in group $\mathrm{K}$ was more than group $\mathrm{F}$ at $2,30,40,90,120,150$ minutes, $(p$ value $<0.05)$. There was no statistical difference in diastolic blood pressure (DBP) between group $\mathrm{K}$ and group $\mathrm{F}$. The value of mean blood pressure recorded in group $\mathrm{K}$ and group $\mathrm{F}$ were statistically significant at 2, 8, 20, 25, 30, 40, 50, 60 minutes, (Figure 3). The mean values of respiratory rate and oxygen saturation were comparable and found no statistically significant difference in group $\mathrm{K}$ and group $\mathrm{F}$.

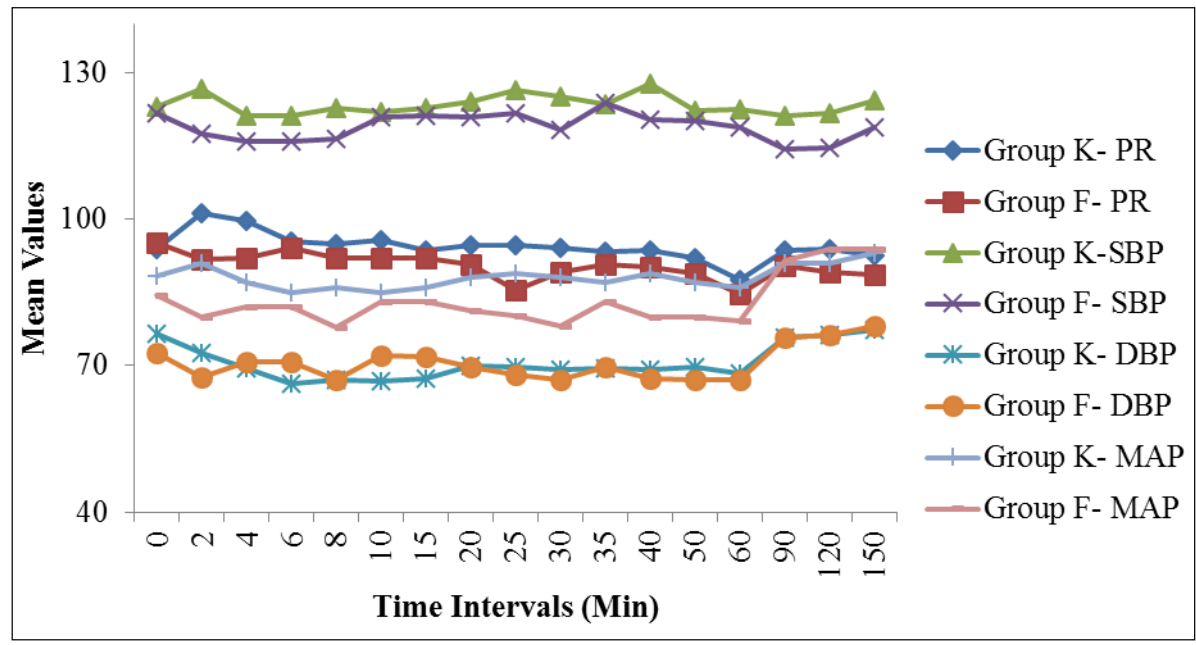

Fig 3: Comparison of haemodynamic parameters between two groups 
Incidence of Hypotension \& bradycardia was higher in group $\mathrm{F}$ than in group $\mathrm{K}$ which was statistically significant $(p<0.05)$. Tachycardia was found in $16.66 \%$ cases in group $\mathrm{K}$, whereas no patient developed tachycardia in group $\mathrm{F}$, the difference was statistically highly significant. (Table 3).

Table 3: Comparison and incidence of side effects between two groups

\begin{tabular}{|c|c|c|c|}
\hline Side effects & Group K & Group F & P-Value \\
\hline Hypotension & $3(10 \%)$ & $11(36.67 \%)$ & 0.014 \\
\hline Pruritus & $0(0 \%)$ & $0(0 \%)$ & 0.0 \\
\hline Shivering & $0(0 \%)$ & $0(0 \%)$ & 0.0 \\
\hline Bradycardia & $0(0 \%)$ & $7(23.33 \%)$ & 0.007 \\
\hline Tachycardia & $5(16.66 \%)$ & $0(0 \%)$ & 0.005 \\
\hline Respiratory depression & $0(0 \%)$ & $0(0 \%)$ & 0.0 \\
\hline
\end{tabular}

\section{Discussion}

Spinal anaesthesia is the most popular regional anaesthetic technique in parturient undergoing caesarean section as it is easy to perform, has rapid and predictable onset, produces more intense and complete block and has very high success rate ${ }^{[9]}$. Various additives such as clonidine, midazolam, fentanyl, ketamine etc. in different doses have been used in combination with local anaesthetic that can effectively help in reduction of the dose of local anaesthetic which leads to early motor recovery and also can increase the duration of analgesia ${ }^{[10]}$., There are various studies available with use of intrathecal fentanyl in LSCS with varying doses like 7.5 $\mathrm{mcg}^{[11]}, 12.5,20 \mathrm{mcg}^{[12,13]}$ and $25 \mathrm{mcg}^{[13,14]}$. From the results of previous studies, $25 \mu \mathrm{g}$ of fentanyl is associated with higher incidence of adverse effects like pruritus ${ }^{[15-17]}$. Ketamine is a potent analgesic at sub anaesthetic plasma concentrations and its analgesic and anaesthetic effect may be mediated via non-competitive antagonism at $N$-methyl d-aspartate (NMDA) receptors ${ }^{[6]}$, In most of the studies doses of ketamine used was $25 \mathrm{mg}$ and they observed some of side effects like nystagmus, nausea, vomiting, and sedation $[9,18]$. Therefore we used lower dose of ketamine (10mg) and fentanyl $(12.5 \mathrm{mcg})$ with bupivacaine $(10 \mathrm{mg})$ to study and compare the onset and duration of sensory and motor block, hemodynamic parameter, foetal wellbeing and side effects such as nausea, vomiting, pruritus, respiratory depression.

In our study, onset of sensory and motor block was faster in ketamine group as compared to fentanyl group and the difference in the onset time for the two drugs was statistically significant, $(p<0.05)$. These results are in accordance with the studies by Jamadar NP et al. \& Shrestha SK et al. ${ }^{[18-20]}$. In group K maximum level of sensory block achieved was $\mathrm{T}_{4}(16.67 \%)$ while its median value was $\mathrm{T}_{6}$ and in group $\mathrm{F}$, maximum level of sensory block achieved was $\mathrm{T}_{4}(43.33 \%)$ while its median value was $\mathrm{T}_{6}$. Unlugenc et al. ${ }^{[19]}$ showed maximum level of sensory block in ketamine $(0.05 \mathrm{mg} / \mathrm{kg})$ and fentanyl $(25 \mathrm{mcg})$ group as T3. These results vary might be because of dosage used, dose used in fentanyl group was on higher side as compared to our study.Patel et al. ${ }^{[9]}$ observed that highest level of sensory block (median) with use of intrathecal ketamine $(25 \mathrm{mg})+$ bupivacaine $(1.8 \mathrm{ml})$ was T5. Similarly Shrestha $e t$ al. ${ }^{[20]}$ found that the highest level of sensory block both in ketamine ( $2 \mathrm{ml}$ bupivacaine $+25 \mathrm{mg}$ ketamine) and fentanyl ( $2 \mathrm{ml}$ bupivacaine $+25 \mathrm{mcg}$ fentanyl) group was T5. This higher level of sensory block may be because dosages used in their study were on higher side.
The total duration of sensory and motor block was significantly prolonged in ketamine group as compared to fentanyl group and which was statistically significant. This result is similar to the study done by Khezri et al. ${ }^{[21]}$ but duration of sensory block in our study was longer than their study. This may be because they had considered regression level up to T10, while in our study we have considered duration of sensory block up to L1. Unlike the present study, Unlugenc et al. ${ }^{[19]}$ observed duration of sensory block was shorter in ketamine group $(95.7 \pm 20.4 \mathrm{~min})$ as compared to fentanyl group $(114.5 \pm 31.8 \mathrm{~min})$; this may be because they have used lower doses of ketamine $(0.05 \mathrm{mg} / \mathrm{kg})$ and higher doses of fentanyl $(25 \mathrm{mcg})$ as compared to our study.

There was no statistical difference between Apgar score of both ketamine and fentanyl group at 1 and $5 \mathrm{~min}$ which is comparable to Jamadar et al. ${ }^{[18]}$ and Biswas et al. ${ }^{[22]}$ study. SBP were higher in ketamine group as compared to fentanyl group at 2, 30, 40, 90,120,150 minutes $(\mathrm{P}$ value $<0.05)$. This result is correlated well with the previous studies ${ }^{[9,20]}$. The difference between diastolic pressures of both the group shows no statistically significant difference, this result is similar to Shrestha et al. ${ }^{[20]}$. The mean arterial pressure of ketamine group was higher than that of fentanyl group at 2, $8,20,25,30,40,50,60$ minutes, $(P$ value $<0.05)$. Hypotension occurred in 3 patients of ketamine group and 11 patients of fentanyl group, which did not require any treatment. In Jamadar et al. ${ }^{[18]}$ study 2 patients of ketamine $(25 \mathrm{mg}$ ) group were having hypotension so these results are comparable to our study. In our study bradycardia was seen in 7 patients in group $\mathrm{F}$ which was corrected with single dose of inj. atropine $0.3 \mathrm{mg}$ intravenously whereas none of the patient developed bradycardia in ketamine group, these results was similar to Biswas et al. (21) who observed bradycardia in 4 patients out of 20 patients in fentanyl group $(12.5 \mathrm{mcg})$. Tachycardia was controlled with single dose of inj Esmolol $10 \mathrm{mg}$ Side effects such as pruritus, respiratory depression, nausea and vomiting in both the We did not observe groups.

\section{Conclusion}

The combination of hyperbaric bupivacaine $(0.5 \%) 10 \mathrm{mg}$ with ketamine (10mg) can be used as a safe and effective alternative to hyperbaric bupivacaine $(0.5 \%) 10 \mathrm{mg}$ with fentanyl $12.5 \mathrm{mcg}$ for spinal anaesthesia in caesarean section as, it provides comparable sensory and motor block characteristics, better haemodynamics with good foetal wellbeing.

\section{Acknowledgement}

The authors sincerely thank the Department of Anaesthesiology, OBGY, other staff of operation theatre for their valuable help. We are grateful to administration of MGM Hospital, Aurangabad, Maharashtra, for giving permission to study and providing facility to carry out the work.

\section{References}

1. Rollins M, Lucero J. Overview of anesthetic considerations for Cesarean delivery, British Medical Bulletin. 2012; 101(1):105-125.

2. Abhinav AV, Harshavardhan. A Comparative Study Between 0.5\% Hyperbaric Bupivacaine and 0.5\% Hyperbaric Bupivacaine with $25 \mathrm{Mcg}$ Fentanyl in Spinal Anaesthesia in Obstetric Patients Undergoing 
Elective LSCS. Journal of Evolution of Medical and Dental Sciences. 2015; 4(27):4636-4643.

3. Gunaydin B, Tan ED. Which local anesthetic at what dose is recommended for parturients undergoing cesarean delivery under spinal anesthesia? J AnesthClin Res. 2016; 7(11):1000681.

4. Goma HM, Flores-Carrillo JC, Whizar-Lugo V, Whizar-Lugo V. Spinal additives in subarachnoid anaesthesia for cesarean section. Topics in Spinal Anaesthesia: In Tech, 2014.

5. Hindle A. Intrathecal opioids in the management of acute post-operative pain. Continuing education in anaesthesia. 2008; 63(6):521-526.

6. Shrestha SK, Bhattarai B, Shah R. Comparative Study of hyperbaric bupivcaine plus Ketamine Vs Bupivacaine plus fentanyl for spinal anaesthesia during caserean section. Kathmandu university med. J. 2013; 44(4):287-291.

7. Kathirvel S, Sadhasivam S, Saxena A, Kanan TR, Ganjoo P. Effects of intrathecal ketamine added to bupivacaine for spinal anaesthesia. Effects. 2000; 55:899-910.

8. Murali Krishna T, Panda NB, Batra YK, Rajeev S. Combination of low doses of intrathecal ketamine and midazolam with bupivacaine improves postoperative analgesia in orthopaedic surgery. European Journal of Anaesthesiology. 2008; 25(4):299-306.

9. Patel ILA, Ghandhi R, Shah A, Bhatt M, Suthar A. Comparative study of bupivacaine vsbupivacaine + ketamine (intrathecally) during intraoperative and postoperative analgesia in non PIH caesarian section. National Journal of Medical Research. 2011; 1(2):7175 .

10. Swain A, Nag DS, Sahu S, Samaddar DP. Adjuvants to local anesthetics: Current understanding and future trends. World J Clin Cases. 2017; 5(8):307-323.

11. Chu CC, Shu SS et al. The effect of intrathecal bupivacaine with combined fentanyl in cesarean section. Acta Anesthesiologica Sin. 1995; 33(3):149154.

12. Bidikar M, Mudakanagoudar MS, Santhosh MCB. Comparison of Intrathecal Levobupivacaine and Levobupivacaine plus Fentanyl for Cesarean Section. Anesth Essays Res. 2017; 11(2):495-498.

13. Yesuf KA, Gebremedhn EG, Melkie TB. Analgesic Effect of Intrathecal Fentanyl as an Adjuvant to Spinal Anaesthesia in Comparison with Spinal Anaesthesia with Bupivacaine Only for Mothers Delivered by Emergency Cesarean Section. J Anesth Crit Care Open Access. 2017; 7(5):00278.

14. Venkata HG, Pasupuleti S, Pabba UG, Porika S, Talari G. A randomized controlled prospective study comparing a low dose bupivacaine and fentanyl mixture to a conventional dose of hyperbaric bupivacaine for cesarean section. Saudi J Anaesth. 2015; 9:122-7.

15. Ali MA, Ismail S, Sohaib M, Aman A. A double-blind randomized control trial to compare the effect of varying doses of intrathecal fentanyl on clinical efficacy and side effects in parturients undergoing cesarean section. J Anaesthesiol Clin Pharmacol. 2018; $34: 221-6$

16. Belzarena SD. Clinical effects of intrathecally administered fentanyl in patients undergoing caesarean section. Anesth Analg. 1992; 74:653-7.
17. Seewal R, Shende D, Kashyap L, Mohan V. Effect of addition of various doses of fentanyl intrathecally to $0.5 \%$ hyperbaric bupivacaine on perioperative analgesia and subarachnoid-block characteristics in lower abdominal surgery: A dose-response study. RegAnesth Pain Med. 2007; 32:20-6.

18. Jamadar NP, Khade G, Ghuge S, Shiledar V, Lanjewar. Comparative Study of Intrathecal Administration of Bupivacaine - Ketamine with Bupivacaine -Tramadol in Patients for Non PIH caesarean Section. Indian Journal of Basic and Applied Medical Research. 2013; 3(1):184-192.

19. Unlugenc H, Ozalevli M. Andana. A double blind comparision of intrathecal ketamine and fenanyl combined bupivacaine $0.5 \%$ for caesarean delivery. European Journal of Anaesthesiology. 2006; 23:10181024.

20. Shrestha SK, Bhattarai B, Shah R. Comparative Study of hyperbaric bupivcaine plus Ketamine Vs Bupivacaine plus fentanyl for spinal anaesthesia during caserean section. Katmandu university med. J. 2013; 44(4):287-291.

21. Khezri MB, Tahaei E, Atlasbaf AH. Comparison of postoperative analgesic effect of intrathecal ketamine and fentanyl added to bupivacaine in patients undergoing cesarean section: A prospective randomized double-blind study. Middle East J Anaesthesiol. 2016; 23(4):427-36.

22. Biswas BN, Rudra A, Bose BK, Nath S, Chakrabarty S, Bhattacharjee S. Intrathecal fentanyl with hyperbaric bupivacaine improves analgesia during caesarean delivery and in early post-operative period. Indian $\mathrm{J}$ Anaesth. 2002; 46(6):469-472. 